\title{
ASSOCIAÇÃO ENTRE RENDA FAMILIAR E A PERCEPÇÃO DOS CONSUMIDORES SOBRE AS ESTRATÉGIAS DE MARKETING VERDE
}

\author{
ASSOCIATION BETWEEN FAMILY INCOME AND CONSUMER PERCEPTION \\ ON GREEN MARKETING STRATEGIES
}

Angelita Freitas da Silva

Instituto Federal de Educação, Ciência e Tecnologia - Brasil angelita.silva@erechim.ifrs.edu.br

ORCID: http://orcid.org/0000-0002-1046-4795

\section{Cassiana Bortoli}

Universidade Federal do Paraná - Brasil

cassianabortoli@gmail.com

ORCID: http://orcid.org/0000-0003-1307-2110

\section{Silvana Saionara Gollo}

Instituto Federal de Educação, Ciência e Tecnologia - Brasil silvana.gollo@erechim.ifrs.edu.br

ORCID: http://orcid.org/0000-0002-2229-1510

\section{Keila Cristina da Rosa}

Instituto Federal de Educação, Ciência e Tecnologia - Brasil

keila.rosa@erechim.ifrs.edu.br

ORCID: http://orcid.org/0000-0003-4557-6372

\begin{abstract}
Submissão: ||/02/20|9. Aceitação: 15/02/2020.
Publicação: 31/03/2020. Sistema de avaliação: Double blind review. Universidade FUMEC / FACE, Belo Horizonte

- MG, Brasil. Editores Prof. Dr. Mário Teixeira Reis Neto Prof. Dr Cid Gonçalves Filho.
\end{abstract}

\section{RESUMO}

As organizações têm buscado estratégias de marketing perante as exigências de consumidores e da sociedade, cada vez mais preocupados com os aspectos relacionados à sustentabilidade. $O$ presente trabalho objetivou analisar a associação entre as faixas de renda familiar e o comportamento do consumidor sobre o marketing verde praticado pelas empresas. Para tanto, utilizou-se uma metodologia exploratória e quantitativa, com aplicação de 373 questionários, analisados por meio dos testes de distribuição de frequência, Correlação de Spearman e Alfa de Cronbach. Os resultados mostraram que contrariando os indícios encontrados na literatura, existe uma relação negativa entre o maior nível de renda familiar e a percepção dos consumidores sobre as estratégias de marketing verde.

\section{PALAVRAS-CHAVE}

Marketing verde. Consumo sustentável. Comportamento do consumidor. Estratégias de marketing. Renda familiar. 


\section{ABSTRACT}

Organizations have been pursuing marketing strategies in response to the demands of consumers and society increasingly concerned with sustainability issues. The present study aimed to analyze the association between the family income brackets and the consumer behavior on the green marketing practiced by the companies. For that, an exploratory and quantitative methodology was used, with application of 373 questionnaires, analyzed through frequency distribution tests, Spearman's Correlation and Cronbach's Alpha.The results showed that contrary to the evidence found in the literature, there is a negative relationship between the higher level of family income and consumer perception of green marketing strategies.

\section{KEYWORDS}

Green marketing. Sustainable consumption. Consumer behavior. Marketing strategies. Family income.

\section{INTRODUÇÃO}

A humanidade começa a redirecionar sua caminhada em busca de um futuro mais sustentável, ao invés de continuar rumando para o consumismo, pensando apenas no bem-estar momentâneo, sem preocupações com a sobrevivência em longo prazo (ASSADOURIAN, 20I0). Nesse sentido, é necessário que ocorram mudanças de hábitos e comportamentos fundamentais (SCHENINI et al., 20I4). As organizações têm buscado tomar medidas para a gestão sustentável e o desenvolvimento de ações de marketing verde, em consequência de a temática ter ganhado força no decorrer das últimas décadas (OTTMAN, 20 I I).

O crescente interesse dos consumidores e das empresas pelo marketing verde, configura-se como uma excelente abordagem estratégica e de posicionamento de mercado (SCHENINI et al., 20I4). As empresas devem analisar cuidadosamente 0 comportamento dos consumidores, a fim de projetar e promover produtos adequados a estes. Ao adotar uma postura pró-ativa perante demanda para os produtos verdes, esta carecerá do uso de uma variedade de ferramentas de marketing verde (REX; BAUMANN, 2007).

Embora os consumidores possam ter um interesse em adquirir produtos verdes, os mesmos podem não refletir tal interesse nas suas percepções sobre o marketing verde, uma vez seu interesse não necessariamente representa seu poder de compra. Dentro desse contexto, os pesquisadores Nascimento et al. (2017) concordam que a renda é uma importante variável demográfica a ser cotrolada quando estudado a percepção do consumidor em relação às estratégias de marketing verde. Os autores destacam ainda que, na empresa analisada, o perfil do consumidor que adquire produtos verdes está concentrada nas classes sociais mais elevadas. Assim, a renda pode atingir de forma significativa seu poder de compra em relação aos produtos 
sustentáveis, de forma que a percepção do marketing verde para os consumidores de baixa renda podem ser distinto.

Foram pesquisados diversos artigos nacionais e internacionais que abordaram a temática, porém esses utilizam a renda somente como variável de controle, não associando de forma aprofundada as duas variáveis. Dessa forma, o problema de pesquisa pode ser resumido da seguinte forma: Qual é a associação entre as faixas de renda familiar e o comportamento do consumidor sobre o marketing verde? A fim de estudar melhor a problemática exposta, o presente estudo objetivou associar as faixas de renda familiar e à percepção do consumidor sobre o marketing verde.

Diante desse contexto, o presente trabalho justifica-se pela importância científica do estudo do comportamento do consumidor verde. $O$ marketing verde não é um tema novo no campo de estudos de marketing, porém tem ganhado relevância (OTTMAN, 20I I). Isso porque, as empresas ainda necessitam melhorar seu entendimento sobre como pôr em prática tal conceito (PAPADAS; AVLONITIS; CARRIGAN, 20I7), e compreender a associação deste com o perfil do consumidor (RODRIGUES et al., 20I3) e sua predisposição à adoção de produtos verdes (REX; BAUMANN, 2007). Tal fato exige mudança de posicionamento, no que tange a segmentação deste público e o uso das ferramentas de marketing verde (REX; BAUMANN, 2007).

É preciso buscar subsídios para que as organizações consigam realizar a readequação de seus processos e do papel da empresa na sociedade, bem como a maneira de comunicar estas questões, utilizando o marketing verde como uma valiosa estratégia mercadológica de forma mais completa (SCHENINI, et al., 20 I4). No âmbito acadêmico, verifica-se que o tema não é muito explorado, sendo considerado ainda embrionário, representado apenas 6,88\% das publicações em marketing entre os anos de 2006 e 2015 (LOPES; FREITAS, 2016). O conhecimento a respeito do assunto abordado representa fonte de informação relevante o somente para o desenvolvimento de estratégias por parte das empresas e organizações, mas também, para os acadêmicos interessados na temática, e demais pesquisadores que pretendem abordar o assunto em pesquisas futuras (CARDOSO; VAN SCHOOR, 2017).

\section{COMPORTAMENTO DO CONSUMIDOR E ESTRATÉGIAS DE MARKETING VERDE}

A sociedade contemporânea mostra-se cada vez mais consciente de seus direitos, preocupada com a qualidade de vida e com a preservação do planeta (LOPES; PACAGNAN, 20l4). Dessa forma, os consumidores passaram a pensar mais sobre as consequências dos processos produtivos em relação ao meio ambiente, tornando a sustentabilidade um tema muito relevante (OTTMAN, 20I I). Cardoso e Van Schoor (2017) afirmam que desde os anos 1970, têm-se realizado estudos a respeito da consciência ecológica dos consumidores. No entanto, o tema começou a ser mais presente no início dos anos 1990, época em que muitos aspectos diferentes do marketing verde foram discutidos academicamente (REX; BAUMANN, 2007).

$\mathrm{Na}$ concepção dos autores Côrtes e Moretti (2013), o consumo verde ainda não é proeminente nas atitudes dos consumidores em diversos países, porém é uma resposta à preocupação ambiental, repercutindo nas estratégias de marketing adotadas pelas empresas. Adicionalmente a esse entendimento, os pesquisadores Barboza e Arruda Filho (2013) evidenciam que 
o consumidor brasileiro se mostra predisposto a aceitação do marketing verde.

Dentre as características do perfil do consumidor adepto à valorização dos produtos e serviços sustentáveis está a constante atualização, a capacidade de ser formador de opinião e a busca por qualidade de vida, e aos fatores que auxiliam as empresas na implantação das estratégias de marketing verde. Essas estratégias geram diferenciação no mercado, através da percepção da organização como um agente de mudança, apresentando uma postura inovadora, preocupando-se com aspectos humanos e ambientais (SCHENINI et al., 20I4).

As organizações têm sido cada vez mais cobradas pelos consumidores para que exerçam de forma efetiva seu papel no processo de sustentabilidade, assumindo valores e práticas sociais, a fim de garantir benefícios não somente à sua organização, mas também para a sociedade como um todo (LOPES; PACAGNAN, 20I4). Dessa forma, elas não podem restringir-se a fornecer $\mathrm{e}$ comercializar produtos e serviços, mas precisam agregar valor econômico, social e ambiental às suas ações, a fim de superar as expectativas dos consumidores e inspirar confiança no mercado, tornando-se um membro participante de mudanças positivas na sociedade (ZENONE; DIAS, 20I5).

Segundo Terres e Branchi (20I3) o crescente uso de ações de sustentabilidade e marketing verde pelas organizações ocorre por motivos como o aspecto legislativo, a fim de cumprir requisitos legais e evitar sanções; também pelo incentivo competitivo, a fim de tornarem-se mais eficientes e reduzir o desperdício; e por motivos éticos, relacionados à preocupação com os seres humanos e a preservação do planeta. Complementarmente, o panorama do mercado atual aponta para a necessidade de estratégias inovadoras e sustentáveis perante a nova postura dos consumidores (LOPES; PACAGNAN, 20I4). Entre outros motivos, as empresas também buscam adequar-se as pressões políticas e sociais, através da adoção de ações de marketing verde (TERRES; BRANCHI, 20I3).

As estratégias de marketing verde visam evitar a degradação ambiental e garantir a sobrevivência e a sustentabilidade financeira das empresas. Tais estratégias culminaram na: exploração do segmento de produtos verdes e serviços verdes; buscam aumentar a produtividade; enquadrar as empresas na legislação vigente; melhorar a imagem institucional; garantir a lucratividade no processo produtivo por meio da oferta de produtos diferenciados; e influenciar a decisão de compra dos consumidores, por meio da utilização de um composto de marketing verde, que inclui a preocupação em desenvolver e comercializar produtos ou serviços ecologicamente corretos, com uma distribuição, preço e comunicação verdes (ENOKI et al., 2008). Neste sentido, o marketing verde apresenta-se como um caminho viável para uma organização obter diferenciais relevantes perante a competitividade acirrada e as exigências do mercado, assumindo um importante papel ambiental e socialmente responsável perante seus consumidores e a sociedade em que está inserida.

As alterações no comportamento do consumidor, em relação a seus valores e necessidades, podem ocorrer por meio de uma percepção mais consciente da realidade. Alterando sua visão de mundo e suas preferências.Verifica-se que, no que se refere ao marketing verde, as expectativas em relação às empresas e produtos passam a estar presentes em todo o ciclo de vida dos mesmos 
(SCHENINI et al., 2014). Exigindo das organizações uma postura consciente em relação a todos os processos que desenvolve.

\section{RENDA FAMILIAR E COMPORTA- MENTO DO CONSUMIDOR EM RELAÇÃO AO MARKETING VERDE}

O perfil do consumidor de produtos sustentáveis tem sido estudado por diversos autores (REX; BAUMANN, 2007;AFONSO, 20 I0; RODRIGUES et al., 20I3). Sendo que a maioria dos esforços sobre o tema tem sido no sentido de identificar as características dos indivíduos e como eles se comportam. Dentre estes, enquadram-se os estudos que objetivam compreender as relações entre as variáveis demográficas e o comportamento verde. Porém, mesmo diante de uma multiplicidade de pesquisas, ainda não se tem um consenso em relação ao perfil do consumidor verde (REX; BAUMANN, 2007).

Neste sentido, alguns estudos apontaram que as mulheres, os jovens e as pessoas com educação e renda relativamente mais elevadas apresentam-se mais propensos a se envolver em comportamentos ambientalmente corretos (AFONSO, 20I0). Já Murin et al. (2015) avalia que o comportamento dos consumidores é influenciado por características como gênero e nível de instrução, sendo que esse último tem importante papel em termos de marketing verde, pois o nível de informação a respeito dos produtos verdes influencia no consumo. No entanto, também são encontrados resultados contraditórios no que tange o papel que a demografia pode desempenhar na identificação do consumidor ecologicamente consciente (RODRIGUES et al., 20I3). As características demográficas são comumente utilizadas como critérios de segmentação de mercado e podem auxiliar no posicio- namento de produtos e serviços para aplicação do marketing verde. De acordo com Rodrigues et al. (20I3), fatores como idade, gênero, renda, escolaridade e classe social, foram investigados por um número relevante de pesquisadores. Pesquisadores têm encontrado correlação positiva entre a renda do consumidor e sua sensibilidade ambiental (RODRIGUES et al., 20I3).

As preocupações ambientais tornaramse mundialmente discutidas e se encontram em todos os níveis de renda, mas fatores como preço, qualidade, conveniência, podem fazer com que a preocupação ambiental se traduza em um comportamento ecologicamente correto (RODRIGUES et al., 20I3). Dentre esses, destaca-se o preço do produto como um fator que certamente influencia $o$ consumidor no momento da decisão de compra (MURIN et al., 20I5) Cabe, às empresas trabalharem com as estratégias de marketing verde, de forma a ofertar produtos mais sustentáveis, que possuam as mesmas características e funções dos produtos comuns, mas que busquem causar menor impacto ao meio ambiente (ENOKI et al., 2008). O uso das estratégias de marketing verde pode motivar os consumidores a efetivarem a troca por produtos verdes (CARDOSO; VAN SCHOOR, 20I7), como por exemplo: a preocupação em utilizar canais de distribuição em que o consumo de recursos e a geração de resíduos seja minimizada (DIAS, 20I0); e o uso de uma comunicação informativa e persuasiva, a fim de auxiliar o consumidor a considerar produtos e serviços verdes em seu conjunto de opções de escolha, bem como, influenciar outros consumidores a adotarem práticas mais sustentáveis (RODRIGUES et al, 20I3).

Pesquisas a respeito do perfil do con- 
sumidor e a importância da questão ambiental no comportamento de consumo tem sido desenvolvidas também no Brasil. Apontando que fatores relacionados ao perfil dos respondentes podem estar ligadas ao comportamento do consumidor em relação ao marketing verde desenvolvido pelas empresas. Como o estudo realizado por Rodrigues et al. (2014) que verificou que quanto mais jovens são os consumidores mais sensíveis às questões ambientais eles são, quanto menor a renda maior a preocupação ambiental e quanto maior a escolaridade, maiores são as atitudes para um comportamento de compra verde.

A partir da contextualização exposta, o presente estudo apresenta as seguintes hipóteses de pesquisa:

$\mathrm{H}_{0}$ :A faixa de renda familiar não está associada com a percepção do consumidor sobre o marketing verde.

$H_{1}$ :A faixa de renda familiar está associada positiva e significativamente com a percepção do consumidor sobre o marketing verde.

\section{METODOLOGIA}

Com intuito de atingir o objetivo proposto, a presente pesquisa classificada como quantitativa quanto à abordagem do problema e descritiva quanto ao objetivo, utilizouse de questionários como técnica de coleta de dados primários, o qual abrangeu uma amostra inicial de 427 respostas, da qual foi necessário eliminar 54 porque não responderam adequadamente à todas as assertivas, totalizando uma amostra final de 373 respostas. $\bigcirc$ questionário foi aplicado aos consumidores da região do Alto Uruguai, compreendendo 40 assertivas mensuradas em escala Likert de 5 pontos, os quais demonstram o grau de concordância ( 1 - discordo totalmente; 2 - discordo parcialmente;
3 - indiferente; 4 - concordo parcialmente e 5 - concordo totalmente), e uma questão para assinalar a faixa de renda familiar (I até 2 salários mínimos; 2 - de 3 a 6 salários mínimos; 3 - de 7 a 10 salários mínimos; 4 - de II a 14 salários mínimos; e 5 - mais de I5 salários mínimos).

Para o processamento dos dados, obteve-se alguns cuidados como: a transformação dos itens do questionário referentes às estratégias de marketing verde, coletados em escala Likert de 5 pontos, para o método aditivo, a fim de obter valores contínuos que representam a composição das dimensões; e a mensuração da renda familiar por meio de variável dummy, a fim de discriminar as faixas para a análise dos dados.

As técnicas de análise dos dados utilizados nessa pesquisa foram: Distribuição de Frequência, Correlação de Spearman e Teste Alfa de Cronbach (FIELD, 2009). A distribuição de frequência mostra quantas vezes um valor ocorreu no conjunto de dados, sendo importante para avaliar a composição dos dados. $O$ teste de Correlação de Spearman é uma estatística não-paramétrica utilizada para detectar a associação entre duas variáveis quando os dados violam a suposição paramétrica (de que os dados apresentam uma distribuição normal). 0 teste Alfa de Cronbach mede a confiabilidade, indicando a consistência da mensuração de um construto. A partir das quais tornase possível atender ao objetivo proposto.

\section{ANÁLISE DOS RESULTADOS}

Dada a importância de compreender a composição dos dados da pesquisa, tendo em vista a análise descritiva das variáveis, utilizou-se a técnica de distribuição de frequência, a partir da qual, sistematizou-se a tabela I, apresentada a seguir: 
TABELA 1 - Distribuição de Frequência

\begin{tabular}{|c|c|c|c|c|c|c|}
\hline \multirow{2}{*}{\multicolumn{2}{|c|}{$\begin{array}{c}\text { Assertivas } \\
1\end{array}$}} & \multicolumn{5}{|c|}{ Grau de concordância } \\
\hline & & \multirow{2}{*}{$\begin{array}{l}2 \\
2,95 \%\end{array}$} & \multirow{2}{*}{$\begin{array}{l}3 \\
5,09 \%\end{array}$} & \multirow{2}{*}{$\begin{array}{c}4 \\
25,47 \%\end{array}$} & \multirow{2}{*}{$\begin{array}{c}\mathbf{5} \\
52,01 \%\end{array}$} & \multirow[b]{2}{*}{$14,48 \%$} \\
\hline \multirow{10}{*}{$\begin{array}{l}\frac{0}{3} \\
\frac{7}{0} \\
\text { 은 }\end{array}$} & $\begin{array}{l}\text { Priorizo a compra de produtos que demonstrem preocupação com a } \\
\text { degradação do meio ambiente }\end{array}$ & & & & & \\
\hline & $\begin{array}{l}\text { Preocupo-me com o impacto negativo que o produto pode causar ao } \\
\text { meio ambiente }\end{array}$ & $1,07 \%$ & $1,34 \%$ & $14,75 \%$ & $55,50 \%$ & $27,35 \%$ \\
\hline & Prefiro produtos cuja matéria-prima é de recursos naturais renováveis & $1,34 \%$ & $4,83 \%$ & $29,49 \%$ & $45,31 \%$ & $19,03 \%$ \\
\hline & Prefiro adquirir produtos que podem ser reciclados ou reutilizados & $1,34 \%$ & $4,29 \%$ & $24,13 \%$ & $47,45 \%$ & $22,79 \%$ \\
\hline & $\begin{array}{l}\text { Costumo verificar se os produtos que estou consumindo agridem o meio } \\
\text { ambiente }\end{array}$ & $2,95 \%$ & $8,04 \%$ & $39,41 \%$ & $41,02 \%$ & $8,58 \%$ \\
\hline & Procuro me informar sobre novos produtos verdes & $6,17 \%$ & $15,55 \%$ & $41,29 \%$ & $29,22 \%$ & $7,77 \%$ \\
\hline & $\begin{array}{l}\text { Verifico na hora da compra, se os produtos possuem embalagens reci- } \\
\text { cláveis }\end{array}$ & $5,09 \%$ & $10,99 \%$ & $40,48 \%$ & $32,98 \%$ & $10,46 \%$ \\
\hline & Compro produtos de materiais reciclados & $2,95 \%$ & $9,12 \%$ & $37,27 \%$ & $41,82 \%$ & $8,85 \%$ \\
\hline & Encontro uma diversidade de produtos sustentáveis no mercado & $12,87 \%$ & $34,85 \%$ & $30,56 \%$ & $18,23 \%$ & $3,49 \%$ \\
\hline & Compro refil de produtos para reutilizar embalagens que já possuo & $3,75 \%$ & $7,51 \%$ & $17,69 \%$ & $38,34 \%$ & $32,71 \%$ \\
\hline \multirow{5}{*}{  } & $\begin{array}{l}\text { Estou disposto(a) a pagar mais por um produto verde que não agride o } \\
\text { meio ambiente }\end{array}$ & $7,77 \%$ & $17,96 \%$ & $31,10 \%$ & $34,05 \%$ & $9,12 \%$ \\
\hline & $\begin{array}{l}\text { Tendo dois produtos de mesma qualidade e mesmo preço, prefiro aque- } \\
\text { le que não agride o meio ambiente }\end{array}$ & $1,61 \%$ & $1,07 \%$ & $10,19 \%$ & $40,48 \%$ & $46,65 \%$ \\
\hline & $\begin{array}{l}\text { Sou motivado a pagar mais por um produto verde, pois tenho consciên- } \\
\text { cia de seus benefícios para a saúde }\end{array}$ & $3,75 \%$ & $11,53 \%$ & $33,24 \%$ & $37,53 \%$ & $13,94 \%$ \\
\hline & $\begin{array}{l}\text { Estou disposto(a) a pagar mais por um produto verde que tem a mesma } \\
\text { qualidade que um produto similar }\end{array}$ & $7,24 \%$ & $13,94 \%$ & $28,95 \%$ & $35,92 \%$ & $13,94 \%$ \\
\hline & Compro produtos em refil por serem mais baratos & $3,49 \%$ & $7,77 \%$ & $20,64 \%$ & $41,55 \%$ & $26,54 \%$ \\
\hline \multirow{6}{*}{ 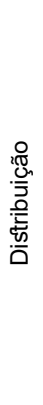 } & Preocupo-me com os locais apropriados para o descarte do produto & $1,88 \%$ & $2,14 \%$ & $10,99 \%$ & $49,33 \%$ & $35,66 \%$ \\
\hline & $\begin{array}{l}\text { Deixaria de adquirir um produto se soubesse que durante seu ciclo de } \\
\text { vida causou algum dano ao meio ambiente }\end{array}$ & $2,41 \%$ & $8,85 \%$ & $33,78 \%$ & $40,21 \%$ & $14,75 \%$ \\
\hline & $\begin{array}{l}\text { Deixaria de adquirir um produto se soubesse que a empresa não dispo- } \\
\text { nibiliza um canal de coleta, reciclagem ou reutilização }\end{array}$ & $2,41 \%$ & $9,65 \%$ & $35,39 \%$ & $41,29 \%$ & $11,26 \%$ \\
\hline & $\begin{array}{l}\text { A propaganda do produto verde nos pontos de venda influenciam a } \\
\text { minha decisão de compra }\end{array}$ & $2,68 \%$ & $7,24 \%$ & $32,98 \%$ & $41,29 \%$ & $15,82 \%$ \\
\hline & Os produtos verdes deveriam estar mais visíveis nos pontos de venda & $0,54 \%$ & $1,88 \%$ & $12,06 \%$ & $41,55 \%$ & $43,97 \%$ \\
\hline & Procuro comprar em locais que vendem produtos verdes & $3,49 \%$ & $7,51 \%$ & $49,87 \%$ & $30,56 \%$ & $8,58 \%$ \\
\hline \multirow{8}{*}{ 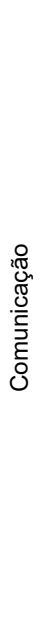 } & $\begin{array}{l}\text { Verifico na embalagem a existência de rótulos ou selos de proteção } \\
\text { ambiental }\end{array}$ & $3,75 \%$ & $10,19 \%$ & $45,04 \%$ & $35,66 \%$ & $5,36 \%$ \\
\hline & $\begin{array}{l}\text { Escolho produtos cujas empresas fabricantes realizem divulgação de } \\
\text { suas ações ambientais }\end{array}$ & $3,75 \%$ & $8,31 \%$ & $40,21 \%$ & $37,80 \%$ & $9,92 \%$ \\
\hline & Recebo informações claras sobre o produto verde & $11,26 \%$ & $29,49 \%$ & $35,66 \%$ & $19,30 \%$ & $4,29 \%$ \\
\hline & Deveria haver mais divulgação dos produtos verdes na mídia & $0,54 \%$ & $2,68 \%$ & $10,72 \%$ & $36,73 \%$ & $49,33 \%$ \\
\hline & $\begin{array}{l}\text { As propagandas de produtos verdes na mídia influenciam minha deci- } \\
\text { são de compra }\end{array}$ & $2,68 \%$ & $6,70 \%$ & $30,03 \%$ & $43,16 \%$ & $17,43 \%$ \\
\hline & $\begin{array}{l}\text { As empresas que têm produtos verdes em seu portfólio transmitem uma } \\
\text { boa imagem }\end{array}$ & $1,07 \%$ & $4,83 \%$ & $19,03 \%$ & $48,53 \%$ & $26,54 \%$ \\
\hline & Procuro obter informações sobre os produtos verdes antes da compra & $3,22 \%$ & $11,26 \%$ & $43,43 \%$ & $33,51 \%$ & $8,58 \%$ \\
\hline & $\begin{array}{l}\text { Me sensibilizo com propagandas que ressaltam a preocupação da } \\
\text { empresa com a sustentabilidade }\end{array}$ & $1,61 \%$ & $4,56 \%$ & $27,08 \%$ & $43,43 \%$ & $23,32 \%$ \\
\hline
\end{tabular}




\begin{tabular}{|c|c|c|c|c|c|c|}
\hline \multirow{12}{*}{ 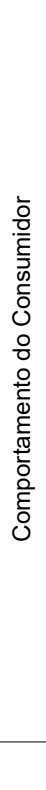 } & $\begin{array}{l}\text { Considero primordial na formação do comportamento de compra a } \\
\text { experiência anterior com o produto }\end{array}$ & $1,34 \%$ & $3,75 \%$ & $24,13 \%$ & $56,03 \%$ & $14,75 \%$ \\
\hline & Estou disposto(a) a gastar mais tempo na procura de produtos verdes & $5,36 \%$ & $16,62 \%$ & $37,53 \%$ & $33,78 \%$ & $6,70 \%$ \\
\hline & Tenho atitudes positivas em relação aos produtos verdes & $1,07 \%$ & $3,49 \%$ & $26,27 \%$ & $53,35 \%$ & $15,82 \%$ \\
\hline & $\begin{array}{l}\text { Minha família influencia para a decisão da aquisição de um produto } \\
\text { verde }\end{array}$ & $8,31 \%$ & $16,89 \%$ & $37,00 \%$ & $30,83 \%$ & $6,97 \%$ \\
\hline & A cultura brasileira estimula a compra de produtos verdes & $17,69 \%$ & $34,05 \%$ & $28,15 \%$ & $15,82 \%$ & $4,29 \%$ \\
\hline & $\begin{array}{l}\text { As atuais informações sobre a degradação do meio ambiente despertou } \\
\text { a necessidade de comprar produtos verdes }\end{array}$ & $0,80 \%$ & $5,63 \%$ & $24,93 \%$ & $45,58 \%$ & $23,06 \%$ \\
\hline & Faz parte do meu estilo de vida comprar produtos verdes & $4,56 \%$ & $16,62 \%$ & $41,29 \%$ & $29,49 \%$ & $8,04 \%$ \\
\hline & Compro determinadas marcas verdes para aceitação da sociedade & $18,50 \%$ & $25,74 \%$ & $37,53 \%$ & $15,28 \%$ & $2,95 \%$ \\
\hline & $\begin{array}{l}\text { Compro produtos verdes porque tenho consciência que é necessário } \\
\text { preservar o meio ambiente }\end{array}$ & $1,88 \%$ & $4,83 \%$ & $26,54 \%$ & $45,58 \%$ & $21,18 \%$ \\
\hline & $\begin{array}{l}\text { Procuro consumir somente produtos que causam menor dano ao meio } \\
\text { ambiente }\end{array}$ & $4,29 \%$ & $10,46 \%$ & $36,19 \%$ & $38,61 \%$ & $10,46 \%$ \\
\hline & $\begin{array}{l}\text { Meu comportamento de compra pode ser alterado ao saber que alguns } \\
\text { produtos degradam o meio ambiente }\end{array}$ & $1,88 \%$ & $4,83 \%$ & $28,15 \%$ & $43,97 \%$ & $21,18 \%$ \\
\hline & Renda Familiar & $35,39 \%$ & $46,65 \%$ & $12,87 \%$ & $3,75 \%$ & $1,34 \%$ \\
\hline
\end{tabular}

Fonte: Adaptado de Enoki et al. (2008).

A partir da tabela I é possível analisar como se dá o comportamento do consumidor sobre o composto de marketing verde considerando a concentração do grau de concordância da maior parte dos respondentes. Na concepção de Schenini et al. (2014) o posicionamento do mercado se dá com relação ao interesse dos consumidores e empresas sobre o marketing verde. A análise individual dos blocos desse composto pode ser importante para os leitores e para as pesquisas futuras da área de marketing que venham a estudar com maior profundidade o tema. Além de que, as empresas podem valer-se dos dados aqui analisados para tomar decisões estratégicas em relação a seu posicionamento sobre o composto de marketing verde: produto, preço, distribuição, comunicação e comportamento do consumidor.

Em relação ao composto de marketing verde "produto", pode-se perceber um comportamento crescente em relação à intenção e comportamento de compra dos consumidores questionados e as estratégias de marketing utilizadas pelas empre- sas. Sendo as estratégias utilizadas pelas empresas colocadas em evidência quando a maior parte dos consumidores $(34,85 \%)$ atribuem um grau de concordância " 2 " (em uma escala de I a 5) para a assertiva "Encontro uma diversidade de produtos sustentáveis no mercado". Esse resultado remete a alguns questionamentos básicos sobre o comportamento do consumidor e as estratégias utilizadas pelas empresas: As empresas oferecem pouca variedade de produtos sustentáveis? As empresas estão ofertando produtos sustentáveis em mercados que seus consumidores realmente frequentam? E, as empresas estão utilizando adequadamente as estratégias de marketing verde, ou os consumidores é que não estão percebendo a existência de produtos sustentáveis nas prateleiras? Essas interrogativas podem ser utilizadas em pesquisas futuras, tendo em vista uma compreensão mais aprofundada com relação ao aspecto levado em consideração na assertiva.

Além disso, percebe-se que os consumidores possuem um comportamento mediano em relação as assertivas: "procuro 
me informar sobre novos produtos verdes" (4I,29\%) e "verifico na hora de compra, se os produtos possuem embalagens recicláveis" (40,48\%). As assertivas as quais os respondentes atribuíram grau de concordância "4" foram:"priorizo a compra de produtos que demonstrem preocupação com a degradação com o meio ambiente" (52,01\%); "preocupo-me com o impacto negativo que o produto pode causar ao meio ambiente" (55,50\%); "prefiro produtos cuja a matéria-prima é de produtos naturais renováveis" (45,3 I\%);"prefiro adquirir produtos que podem ser reciclados ou reutilizados" (47,45\%); "costumo verificar se os produtos que consumo agridem o meio ambiente" (4I,02\%); "compro produtos com materiais reciclados" (4I,82\%); e, "compro refil de produtos para reutilizar embalagens que já possuo”. Pode-se destacar também uma possível tendência evolutiva dos respondentes para atribuição "5" ao grau de concordância sobre as assertivas:"compro refil de produtos para reutilizar embalagens que já possuo” (em que já se concentram 32,71\% dos respondentes); e, "preocupo-me com o impacto negativo que o produto pode causar ao meio ambiente" (em que já se concentram 27,35\% dos respondentes).

Com relação ao "preço", observa-se que há maior dispersão dos dados, indicando que essa pode ser a questão mais sensível do composto de marketing verde. Em pelo menos "3" das "5" assertivas correspondentes a esse aspecto, percebe-se a movimentação do comportamento do consumidor para uma tendência de maior consumo de produtos verdes: "estou disposto (a) a pagar mais por um produto verde que não agride o meio ambiente" (grau de concordância $3-31,10 \%$; e, grau de concordância 4 - 34,05\%);"sou motivado a pagar mais por um produto verde, pois tenho consciência de seus benefícios para a saúde" (grau de concordância 3 - 33,24\%; e, grau de concordância 4 - 37,53\%); e, "estou disposto (a) a pagar mais por um produto verde que tem a mesma qualidade de um produto similar" (grau de concordância 4 - 35,92\%). As outras " 2 " assertivas "tendo dois produtos de mesma qualidade e mesmo preço, prefiro aquele que não agride o meio ambiente " e "compro produtos em refil por serem mais baratos" estão bastante relacionadas à oportunidade de se obter um produto sustentável pelo mesmo preço ou mais barato, de forma que foram atribuídos grau de concordância correspondentes de "5" (46,65\%) e "4" (4I,55\%). Esse achado parece estar de acordo com a literatura existente, uma vez que os pesquisadores Nascimento et al. (20l7) destacam que a renda pode ser um fator limitante na aquisição de produtos sustentáveis. Contudo, esse indício pode ser melhor analisado a partir do teste de Correlação de Spearman.

As respostas dos consumidores em relação ao componente de marketing verde “distribuição", também pode alertar as empresas sobre alguns cuidados a se ter ao reformular estratégias. Os respondentes indicaram concordar a um grau de "4" (49,33\%) e "5" (35,66\%) sobre a assertiva "preocupo-me com os locais apropriados de descarte do produto". Além de emitirem um alerta às empresas quanto ao grau de concordância "4" sobre as assertivas: "deixaria de adquirir um produto se soubesse que durante seu ciclo de vida causou algum dano ao meio ambiente" (40,21\%); "deixaria de adquirir um produto se soubesse que a empresa não disponibilizaria 
um canal de coleta, reciclagem ou reutilização" (4I,29\%); e, "a propaganda do produto verde nos pontos de venda influenciam a minha decisão de compra" $(4 I, 29 \%)$.

Outro fator que chamou bastante a atenção e que pode estar associado ao baixo grau de concordância $(34,85 \%)$ atribuído à assertiva pertencente ao componente produto "encontro uma diversidade de produtos sustentáveis no mercado" é a assertiva "os produtos verdes deveriam estar mais visíveis nos pontos de venda" o qual obteve um grau de concordância " 5 " (por $43,97 \%$ dos respondentes). Esse indicativo deve alertar as empresas, principalmente as que estão localizadas na região que se abrangeu nesse estudo, para que aumentem os cuidados em relação às estratégias de marketing verde adotadas, pois, além de praticarem uma ideologia verde, faz parte do propósito de marketing verde influenciar mais pessoas a adquirirem os produtos (REX; BAUMANN, 2007).

É possível destacar alguns aspectos relevantes em relação ao item "comunicação" do composto de marketing verde, de modo que se perceba a importância atribuída pelos consumidores aos itens referentes a esse aspecto, e o quanto eles aguardam que essa comunicação seja feita pela empresa. Esse último indício pode ser levantado a partir do grau de concordância intermediário - 3-com relação às assertivas: "verifico na embalagem a existência de rótulos ou selos de proteção ambiental" (45,04\%); "escolho produtos sujas empresas fabricantes realizam divulgação de suas ações ambientais" (35,66\%); "recebo informações claras sobre o produto verde" (35,66\%); e, "procuro obter informações sobre os produtos verdes antes da compra $(43,43 \%)$. Sendo que os dois primeiros itens e o último item destacado possuem como segundo maior grau de concordância "4", representado respectivamente por $35,66 \%, 37,8 \%$ e $33,51 \%$ dos respondentes, o que parece transparecer a importância atribuída pelos consumidores ao material informativo. $O$ terceiro item destacado, porém, possui como segundo maior grau de concordância "2", representando 29,49\% dos respondentes, o que pode servir como alerta aos profissionais da área de marketing sobre a falta de informações claras sobre o produto que adquirem.

Complementarmente os respondentes atribuíram o grau de importância " 5 " à assertiva "deveria haver mais divulgação dos produtos verdes na mídia" (49,33\%), e complementam atribuindo o grau de importância "4" às assertivas "as propagandas de produtos verdes na mídia influenciam minha decisão de compra" $(43,16 \%)$ e "as empresas que tem produtos verdes em seu portfólio transmitem uma boa imagem" (48,53\%). Esses achados rementem ao entendimento de que se os materiais informativos sobre os produtos verdes utilizassem mais da mídia, provavelmente os consumidores seriam convencidos a adquirir maior quantidade de produtos verdes, além de valorizar a imagem da empresa.

O bloco de assertivas a respeito do comportamento do consumidor mostrou bastante dispersão entre os respondentes, portanto, nesse bloco, foram analisados o grau de importância de maior representatividade. Assim, torna-se possível constatar que as pessoas concordam: pouco (2) que "a cultura brasileira estimula a compra de produtos verdes" (34,05\%); de forma intermediária (3) que "estou disposto (a) a gastar mais tempo a procura de produtos verdes" (37,53\%), “minha família influencia 
para a decisão da aquisição de um produto verde" (37,00\%), "faz parte do meu estilo de vida comprar produtos verdes" $(41,29 \%)$ e "compro determinadas marcas verdes para a aceitação da sociedade" (37,53\%); e possuem um grau de concordância " 4 " em relação às assertivas "considero primordial na formação do comportamento de compra a experiência anterior com o produto" (56,03\%), "tenho atitudes positivas em relação aos produtos verdes" (53,35\%), "as atuais informações sobre a degradação do meio ambiente despertou a necessidade de comprar produtos verdes" (45,58\%), "compro produtos verdes porque tenho consciência de que é necessário preservar o meio ambiente" (45,58\%), "procuro consumir somente produtos que causam menor dano ao meio ambiente" $(38,61 \%)$ e "meu comportamento de compra pode ser alterado ao saber que alguns produtos degradam o meio ambiente" (43,97\%).

Esses achados indicam que historicamente não se teve grandes preocupações em relação ao meio ambiente, uma vez que a cultura e a família influenciam pouco na decisão de compra, mas que as pessoas têm aumentado o nível de preocupação em relação aos produtos que estão adquirindo e as consequências do consumo ao meio ambiente, de forma que esse comportamento deve vir a estimular que as empresas forneçam, cada vez mais, produtos verdes.

Conforme pode ser percebido no quadro de frequência e nas análises realizadas a partir do mesmo, os dados aparentemente indicam não apresentar uma distribuição normal, dado a volatilidade dos resultados. Para a verificação desse indício, utilizou-se o teste não paramétrico Kolmogorov-Smirnov, o qual apresentou p-valor significativamente baixo para todas as variáveis, rejeitando a hipótese nula de que há uma distribuição normal dos dados para todas as variáveis utilizadas. Uma vez obtida essa informação, foi possível definir que o teste de correlação de Spearman (FIELD, 2009) é mais adequado aos dados de pesquisa. Os resultados desse teste são apresentados na tabela 2, a seguir.

TABELA 2 - Matriz de Correlação de Spearman

\begin{tabular}{|c|c|c|c|c|c|c|c|c|c|c|c|}
\hline & P & PR & D & C & CC & $\mathrm{MV}$ & R1 & R2 & R3 & R4 & R5 \\
\hline$P$ & 1,00 & & & & & & & & & & \\
\hline PR & ,606 & 1,00 & & & & & & & & & \\
\hline $\mathrm{D}$ &, $589^{\star \star}$ &, $646^{\star *}$ & 1,00 & & & & & & & & \\
\hline$C$ &, $672^{* *}$ &, $646^{* *}$ & ,709 & 1,00 & & & & & & & \\
\hline $\mathrm{CC}$ & ,671** &, $645^{* *}$ &, $707^{* *}$ &, $769^{* *}$ & 1,00 & & & & & & \\
\hline MV &, $843^{\star *}$ &, $794^{\star *}$ &, $822^{* *}$ &, $884^{\star \star}$ &, $903^{* *}$ & 1,00 & & & & & \\
\hline $\mathrm{R} 1$ & ,040 & ,010 & ,035 &, 015 & ,052 & ,039 & 1,00 & & & & \\
\hline R2 &,- 047 &,- 035 &,- 042 &,- 055 &,- 097 &,- 07 &,$- 692^{* *}$ & 1,00 & & & \\
\hline $\mathrm{R} 3$ & ,024 &, 061 &,- 009 &, 065 & ,03 & ,037 &,$- 227^{\star *}$ &,$- 286^{\star *}$ & 1,00 & & \\
\hline $\mathrm{R} 4$ & ,054 & ,063 & ,086 & ,021 & ,068 & ,070 &,$- 110^{* *}$ &,$- 138^{* *}$ &,- 045 & 1,00 & \\
\hline R5 &,$- 102^{*}$ &,- 056 &,- 051 &,- 075 &,- 097 &,- 100 &,- 077 &,- 097 &,- 032 &,- 015 & 1,00 \\
\hline
\end{tabular}

Fonte: Adaptado de saídas geradas pelo IBM SPSS.

Legenda: ***Significante ao nível de $1 \%$ ** Significante ao nível de $5 \%$ *Significante ao nível de $10 \%$.

P - Produto; PR - Preço; D - Distribuição; C - comunicação; Comportamento do Consumidor; MV - Marketing Verde; R1 - Renda de até 2 salários mínimos; R2 - Renda de 3 a 6 salários Mínimos; R3 - Renda de 7 a 10 salários mínimos; R4 - Renda de 11 a 14 salários mínimos; R5 - Renda superior a 15 salários mínimos. 
A tabela 2 apresenta os resultados das associações entre as variáveis utilizadas na pesquisa, de forma que é possível perceber que as dimensões: produto, preço, distribuição, comunicação e comportamento do consumidor, possuem uma forte associação positiva, uma vez que os coeficientes de correlação se apresentam elevados (de 0,589 a 0,884 ) e com um nível de significância de $5 \%$. Esses resultados fortalecem o entendimento de que tais dimensões associadas, mensuram o construto "Percepção do consumidor sobre o Marketing Verde". A fim de obter maior confiabilidade sobre a métrica, utilizou-se o teste Alfa de Cronbach, devendo esse apresentar valor superior a 0,7 para atestar que um conjunto de variáveis medem de forma conjunta um construto, sendo que se obteve um Alfa de Cronbach de 0,9. Nascimento et al. (20I7) ressaltam que o marketing é uma ferramenta essencial para toda a empresa, devendo ser voltada para o cliente, e atualmente, entende-se que o comportamento do consumidor vai além do intercâmbio econômico, incluindo o consumo e o descarte do produto.

Diversos autores têm demonstrado preocupação com o tema, motivando-os aprofundar os estudos sobre o perfil do consumidor. Dentre as variáveis que formam o perfil, têm-se controlado a variável renda familiar (ENOKI et al., 2008; AFONSO, 20 I0; NASCIMENTO et al., 2017), contudo essa variável não tem sido trabalhada com maior profundidade, tanto em termos teóricos quanto em relação às análises. Nesse sentido, entendeu-se adequado dedicar um estudo para compreender melhor a associação entre as faixas de renda familiar e a percepção do consumidor sobre o marketing verde. Assim, os resultados obtidos a partir do teste de Correlação de Spearman não foram ao encontro da hipótese levantada, uma vez que obteve-se uma correlação negativa (Coef.: -0, I02; P-valor: 0,048) entre a maior faixa de renda familiar e a dimensão produto, além de não apresentar correlações significantes com as demais dimensões da percepção do consumidor sobre o marketing verde. As demais faixas de renda familiar não apresentaram significância estatística para os demais testes de correlação apresentados na matriz.

Em relação à correlação negativa encontrada entre a faixa de renda familiar 5 (a partir de 15 salários mínimos) e a dimensão produto, é possível inferir que o indivíduo classificado nessa faixa renda familiar age de forma inversa em relação ao consumo sustentável. Ou seja: não prioriza a compra de produtos que demonstrem preocupação com a degradação do meio ambiente; não se preocupa com o impacto negativo que o produto pode causar ao meio ambiente; não prefere produtos cuja matéria-prima é de recursos naturais renováveis; não prefere adquirir produtos que podem ser reciclados ou reutilizados; não costuma verificar se os produtos que está consumindo agridem o meio ambiente; não procura se informar sobre novos produtos verdes; não verifica na hora da compra, se os produtos possuem embalagens recicláveis; não compra produtos de materiais reciclados; não encontra uma diversidade de produtos sustentáveis no mercado; e não compra refil de produtos para reutilizar embalagens que já possui. Nesse sentido, os resultados dessa pesquisa diferem dos achados de Nascimento et al. (20I7), que concluiu que o público que costumava frequentar a empresa estudada, permanecem em classes sociais mais elevadas, com poder aquisitivo mais elevado. 
Outros estudos, porém, não encontraram efeito significativo da variável renda para com a conscientização ambiental (AFONSO, 20I0), e outro estudo também não obteve significância ao tentar diferenciar a renda dos segmentos de consumidores verdes (RODRIGUES et al., 20I3). Sendo um resultado semelhante ao obtido para as demais faixas de renda familiar e às dimensões da percepção do consumidor sobre o marketing verde. Esses resultados indicam que os indivíduos classificados nas demais faixas de renda familiar não apresentam uma tendência no comportamento, agindo de forma aleatória.

\section{CONSIDERAÇÕES FINAIS}

Constantemente a sociedade tem demonstrado preocupação com preservação do planeta (LOPES; PACAGNAN, 20I4), de forma que os consumidores começaram a refletir sobre as práticas das empresas e as consequências causadas pelas mesmas (OTTMAN, 20II), passando a exigir que as empresas se adaptem com relação aos produtos ofertados e suas práticas empresariais. No Brasil, os pesquisadores Barboza e Arruda Filho (20I3) evidenciam que o consumidor tem se mostrado predisposto à aceitação do marketing verde, diferente de outros países, como destaca os autores Côrtes e Moretti (20l3), em que o consumo verde ainda não é proeminente nas atitudes dos consumidores.

Diante do atual contexto, as organizações têm sofrido maior cobrança pelo grupo de stakeholders, obrigando-se a exercer de forma efetiva seu papel no processo de sustentabilidade, assumindo valores e práticas sociais, a fim de garantir benefícios não somente da organização, como também para a sociedade como um todo
(LOPES; PACAGNAN, 20I4). Assim, as empresas não podem se limitar a fornecer e comercializar produtos e serviços, mas precisam agregar valor econômico, social e ambiental às suas ações, a fim de superar as expectativas dos consumidores e inspirar confiança no mercado, tornando-se um membro participante de mudanças positivas na sociedade (ZENONE; DIAS, 20I5).

Dessa forma, as empresas que trabalham com estratégias de marketing verde devem instigar os consumidores de que o comportamento desses faz a diferença para a preservação do meio ambiente, de forma a convencê-los a considerar adquirir produtos verdes (RODRIGUES et al. 20l3). Adicionalmente, as empresas devem levar em consideração que os consumidores só farão mudanças nos seus padrões de compra se estiverem convencidos de que suas atitudes em relação à compra de produtos verdes acarretarão em impactos positivos ao meio ambiente, e para tanto, devem conhecer as práticas sustentáveis adotadas pelas empresas. Nesse sentido, poderão decidir de forma consciente e segura sobre suas atitudes enquanto consumidor, e optar por pagar o preço exigido por um produto verde. Isso porque, sabe-se que ao agregar o valor de sustentabilidade a um produto verde, seu preço sofre variações, normalmente elevando-os. A partir desse indício, diversos foram os autores que consideraram a renda familiar como uma variável de controle à percepção do consumidor sobre o marketing verde.

Após a pesquisa bibliográfica acerca do comportamento do consumidor e o marketing verde, percebeu-se que diversas pesquisas (ENOKI et al., 2008; AFONSO, 2010; NASCIMENTO et al., 2017) que relacionam essa variável com o perfil do con- 
sumidor, utilizam a variável demográfica renda familiar. Nesse sentido, acreditava-se que a faixa de renda familiar estaria associada à percepção do consumidor sobre o marketing verde, de modo que consumidores classificados em maior faixa de renda familiar tenderiam a adquirir em maior proporção os produtos verdes se comparados aos consumidores de menores faixa de renda. Apesar dos indícios encontrados na literatura, os quais conduziram a esse entendimento, os resultados dessa pesquisa apontam uma associação negativa entre a maior renda familiar e a percepção de consumo dos produtos verdes (Coef.: -0, I02; P-valor: 0,048). Esse resultado levanta indícios, inclusive, que indivíduos com maior renda familiar (acima de 15 salários mínimos) preferem adquirir produtos não verdes. Corroborando com os resultados de Rodrigues et al. (20l4), que constataram que quanto menor a renda maior a preocupação ambiental. Este resultado conduziu à aceitação da hipótese nula, rejeitando a hipótese alternativa de que a faixa de renda familiar está associada positiva e significativamente com a percepção do consumidor sobre o marketing verde. 


\section{REFERÊNCIAS}

AFONSO, A.C.B. O Consumidor

Verde: perfil e comportamento de compra. Mestrado em Marketing. Universidade Técnica de Lisboa. Lisboa, 2010.

ASSADOURIAN, E. Transforming Cultures: From Consumerism to Sustainability. Journal of Macromarketing, 30(2). Disponível em: <http://jmk.sagepub.com/content/30/2/186.extract>. Acesso em: 05 mar. 2015.

BARBOZA, M. N. L. \& ARRUDA FILHO, E. J. M. Ideologia verde e o comportamento do consumidor tecnológico: preferência de uso e justificação. Pretexto. Belo Horizonte, 20I3, I4(4), p. 98-I I7.

CARDOSO, P. R. \& VAN SCHOOR, $M$. Portuguese consumers' green purchase Behavior: an analysis of its antecedents and a proposal of segmentation. Brazilian Journal of Marketing - BJM. Revista Brasileira de Marketing ReMark. São Paulo, 2017, 16(2), p.I40-I53.

CÔRTES, P. L. \& MORETTI, S. L.

A. Consumo Verde: Um Estudo Transcultural Sobre Crenças, Preocupações e Atitudes Ambientais. REMark - Revista Brasileira de Marketing. São Paulo, 2013, I2(3), p.45-76.

DIAS, S. R. Professores do Departamento de Mercadologia da FGV - EAESP e Convidados. Gestão de marketing. São Paulo: Saraiva, 2010.

ENOKI, P.A.;ADUM, S. H. N.; FERREIRA, M. Z.; AURELIANO, C. A.; \& VALDEVINO, S. L. Estratégias de Marketing Verde na Percepção de
Compra dos Consumidores na Grande São Paulo. Artigo apresentado no III Encontro de Marketing da ANPAD - EMA. Disponivel em: <http://www. anpad.org.br/admin/pdf/EMAI59. pdf>. Acesso em:0I mar. 2018.

FIELD, A. Descobrindo a estatística usando o SPSS. 2. ed. Porto Alegre:Artmed, 2009.

LOPES, V. N. \& PACAGNAN, M. N. Marketing verde e práticas socioambientais nas indústrias do Paraná. R.adm. São Paulo, 20I4, 49(I), p.II6-I28.

LOPES, W. M. O; FREITAS, W. R. S. Marketing ambiental: uma análise da produção científica brasileira. Revista Brasileira de Marketing - REMark, 2016, 15(3), p.355-372.

MURIN, I.; MARKOVÁ, I.; ZELENÝ, J.; JADUDOVÁ, J. Green Marketing a Tool Influencing Consumers Behavior: Slovak Case Study of Regional Mark Preference. Procedia Economics and Finance. Business Economics and Management 2015 Conference - BEM. 2015, 34, p.260-267.

NASCIMENTO, L. M.; SILVA, V. A.; PIVETTA, N. P.; \& SCHERER, F. L. A percepção dos consumidores em relação às estratégias de Marketing desenvolvidas por uma empresa de produtos naturais e orgânicos. Revista Brasileira de Marketing - REMark. 2017, I6(2), p. I68-179.

OTTMAN, J. The new rules of green marketing: strategies, tools, and inspiration for sustainable Branding. San Francisco: Barrett-
-Koehler Publishers, 20 II.

PAPADAS, K.; AVLONITIS, G. J.; \& CARRIGAN. Green marketing orientation: Conceptualization, scale development and validation. Journal of Business Research. 2017, 80, p.236- 246.

REX, E. \& BAUMANN, H. Beyond Ecolabels:What Green Marketing Can Learn From Conventional Marketing. Journal of Cleaner Production. 2007, 15, p.567-576. RODRIGUES, A. R.; GONÇALVES, E. J.V.; COSTA,A. P.; NORA, E. S.; REZENDE, D. C. Marketing Verde e Consumo Consciente - Segmentando o Mercado de Lavras MG. Espacios. 20I3, 34(4), p.I-I2.

RODRIGUES, J. D.; MOREIRA, V.F;; OLIVEIRA, A.M.B.; AGUIAR, E. C.; BARBOSA, O.T. Comportamento de consumo verde: uma análise dos consumidores de Campina Grande. Revista Brasileira de Administração Científica, Aquidabã, 20I4, 5 (I), Jan-Jun, 2014.

SCHENINI, P.C., SCHMITT,V., DA SILVA, F. A. \& PEREIRA, M. F. Marketing Verde como uma abordagem estratégica frente ao novo perfil de consumo. Caderno Profissional de Marketing. Piracicaba, 2014, 2(I), p. I2-24.

TERRES, M. S. \& BRANCHI, I. H. Going Green: consumo sustentável e as estratégias de marketing verde. Raunp. São Paulo, 2013, 5(I), P.33-44.

ZENONE, L. C. \& DIAS, R. Marketing Sustentável: valor social, econômico e mercadológico. São Paulo:Atlas, 2015. 